\title{
An ankylosaurian dinosaur from the Cenomanian Dunvegan Formation of northeastern British Columbia, Canada
}

\author{
Victoria M. Arbour ${ }^{1}$, Derek Larson ${ }^{2}$, Matthew Vavrek ${ }^{3}$, Lisa Buckley ${ }^{4}$, and David Evans ${ }^{3,5}$ \\ ${ }^{1}$ Department of Knowledge, Royal BC Museum, Victoria, BC, V8W 9W2, Canada \\ ${ }^{2}$ Philip J. Currie Dinosaur Museum, Wembley, AB, T0H 3S0, Canada \\ ${ }^{3}$ Department of Natural History, Royal Ontario Museum, 100 Queen's Park, \\ Toronto, Ontario, M5S 2C6, Canada \\ ${ }^{4}$ P.O. Box 647, Rossland, BC, V0G 1Y0, Canada \\ ${ }^{5}$ Department of Ecology and Evolutionary Biology, University of Toronto, \\ 25 Willcocks Street, Toronto, Ontario, Canada
}

Correspondence: Victoria M. Arbour (varbour@royalbcmuseum.bc.ca)

Received: 1 April 2020 - Revised: 7 July 2020 - Accepted: 14 July 2020 - Published: 1 September 2020

\begin{abstract}
Fragmentary but associated dinosaur bones collected in 1930 from the Pine River of northeastern British Columbia are identified here as originating from an ankylosaur. The specimen represents only the second occurrence of dinosaur skeletal material from the Cenomanian Dunvegan Formation and the first from Dunvegan outcrops in the province of British Columbia. Nodosaurid ankylosaur footprints are common ichnofossils in the formation, but the skeletal material described here is too fragmentary to confidently assign to either a nodosaurid or ankylosaurid ankylosaur. The Cenomanian is a time of major terrestrial faunal transitions in North America, but many localities of this age are located in the southern United States; the discovery of skeletal fossils from the Pine River demonstrates the potential for the Dunvegan Formation to produce terrestrial vertebrate fossils that may provide important new data on this significant transitional period during the Cretaceous.
\end{abstract}

\section{Introduction}

Terrestrial vertebrate fossils have rarely been reported from the Cenomanian-aged Dunvegan Formation (Burns and Vavrek, 2014; Vavrek et al., 2014), which crops out in northeastern British Columbia and northwestern Alberta. Here we describe dinosaur bones recovered from outcrops of the formation along the Pine River in northeastern British Columbia (Fig. 1a). The specimen (CMN 59667), a block of sandstone with associated ribs and vertebrae, was collected in 1930 from the Pine River. To our knowledge this is the first dinosaur skeletal fossil discovered in the province, predating by more than 40 years the discovery of Ferrisaurus sustutensis (Arbour and Evans, 2019), first reported by Arbour and Graves (2008).

Although bony fish and sharks have been recorded from the Dunvegan Formation in Alberta (Hay et al., 2007; Cook et al., 2008; Vavrek et al., 2014), the terrestrial vertebrate body fossil record of the formation has thus far been limited to a few ankylosaur ossicles from Alberta (Burns and Vavrek, 2014). Dinosaur bones found in the Tumbler Ridge area, first described as originating from the Dunvegan Formation (McCrea, 2003), were later reinterpreted as originating from the Turonian Kaskapau Formation (McCrea and Buckley, 2004; Rylaarsdam et al., 2006). Therefore, well-preserved dinosaur fossils, particularly from an associated skeleton, would contribute significantly to understanding the fauna of the Dunvegan Formation and preservational potential within this unit.

CMN 59667 is noteworthy for being one of very few Cenomanian-aged dinosaur skeletal fossils from Canada (Brown et al., 2015). Terrestrial Cenomanian assemblages are rare in North America but capture an important time which preserves a distinct and transitional assemblage between characteristic faunas of the Early and latest Late Cretaceous. The nearest comparative material of this age is derived from Dunvegan Formation outcrops in Alberta, the Cedar Mountain Formation of Utah (Avrahami et al., 2018; Tucker 

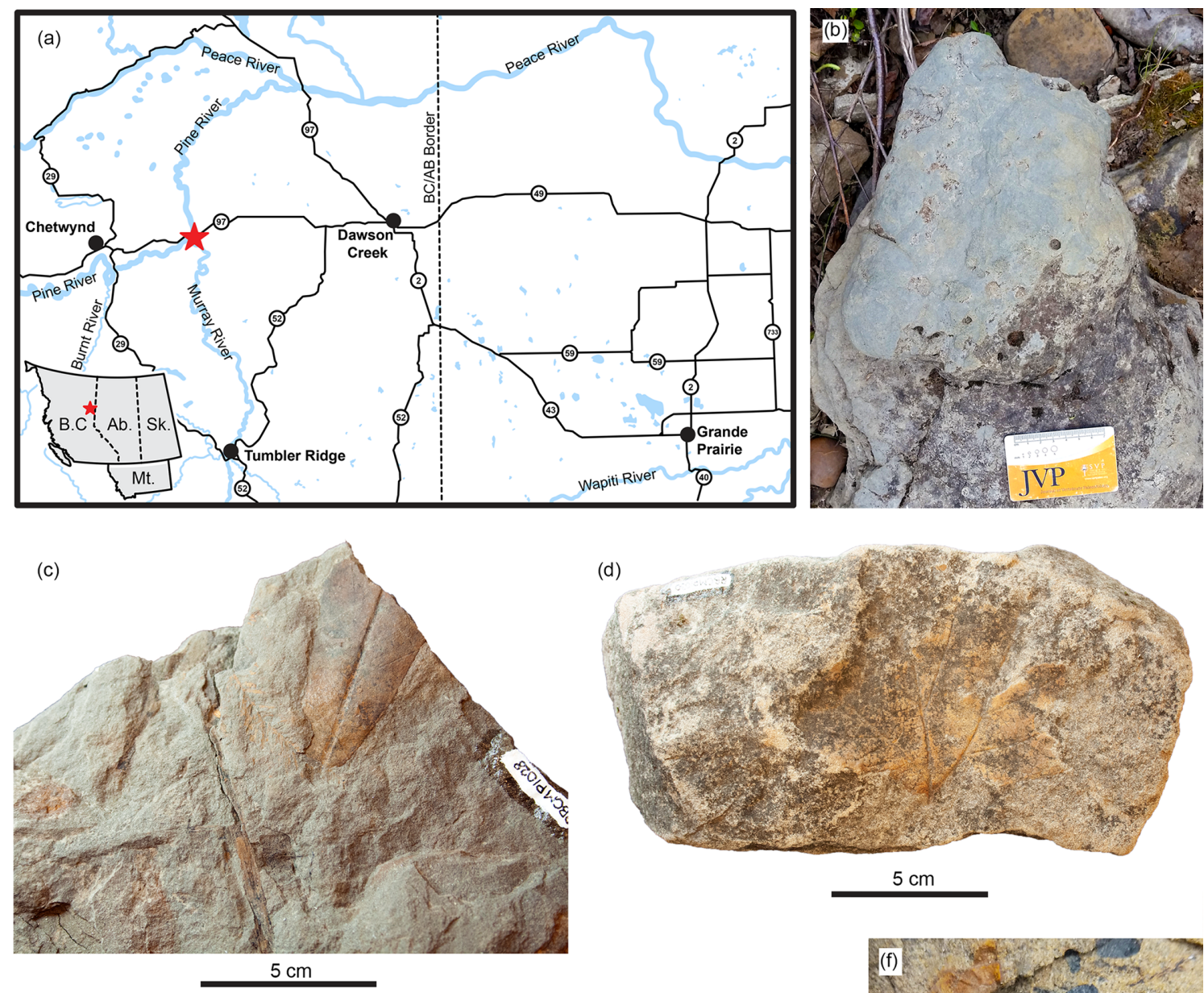

(e)
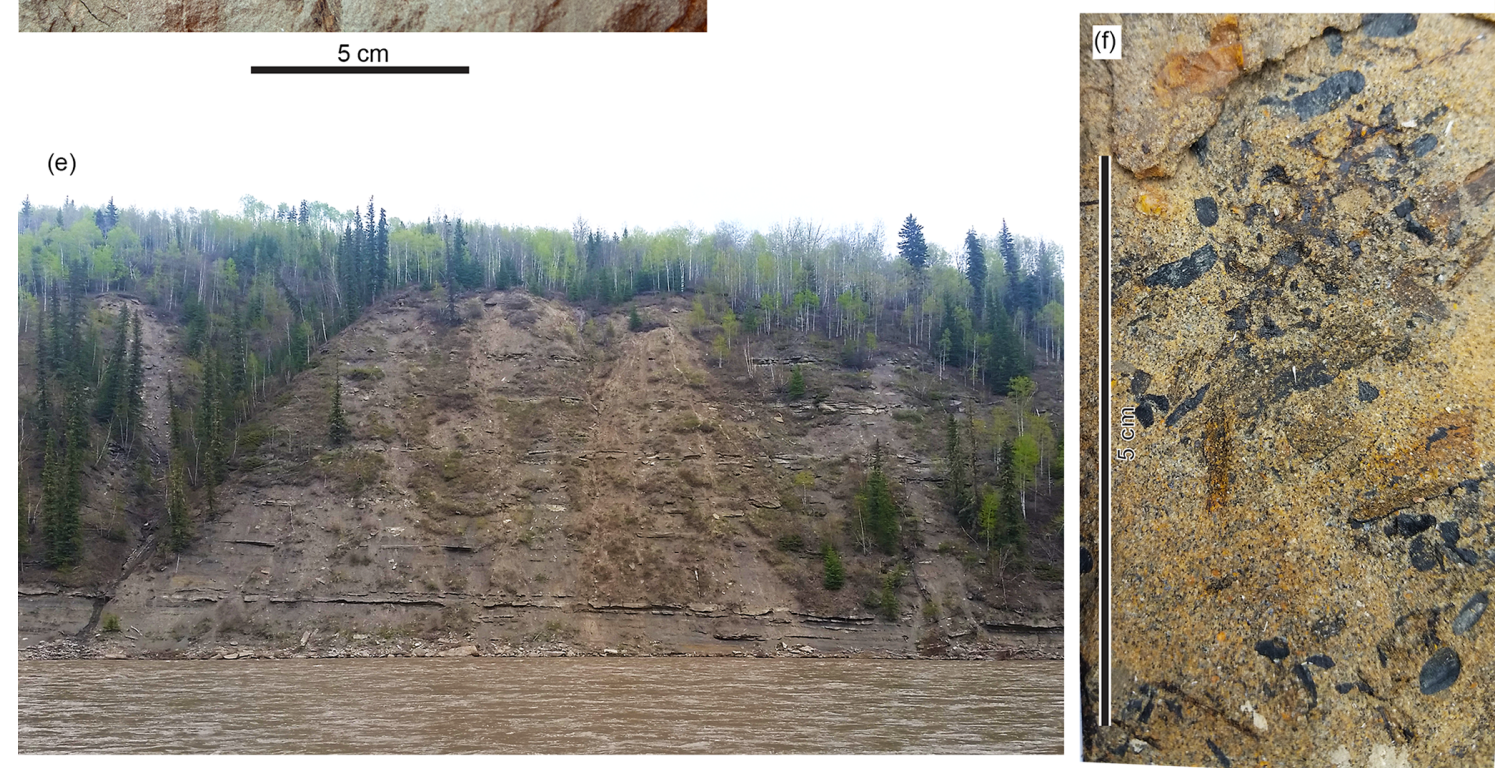

Figure 1. CMN 59667 was collected along the Pine River in northeastern British Columbia, approximately $1.6 \mathrm{~km}$ downstream of its junction with the Murray River. Sedimentological and palaeontological features in this area suggest these are outcrops of the upper two-thirds of allomember E of the Dunvegan Formation. (a) Location of the collection site for CMN 59667 in British Columbia, Canada, indicated by a red star (inset map shows location in western Canada). (b) Tetrapodosaurus pes natural cast (RBCM P1473) discovered at this site; anterior is to the right. (c) RBCM P1028, sample with Metasequoia leaf and obovate or elliptical angiosperm leaf with entire margin (leaf morphotype 122; Ash et al., 1999). (d) RBCM P1030, palmately lobed angiosperm leaf (leaf morphotypes 140-143; Ash et al., 1999). (e) Cliff-forming outcrops on the eastern bank of the Pine River, $1.6 \mathrm{~km}$ from its junction with the Murray River, as viewed from the west bank. (f) Gymnosperm cone in cross section (not collected), observed on the west bank of the Pine River. 
et al., 2020), the Woodbine (Noto et al., 2012) and Paw Paw formations of Texas, the Frontier Formation of Wyoming (Lull, 1921), the Wayan Formation of Idaho (Krumenacker et al., 2019), and the Dakota Formation of the western US (Eaton, 1960; Eaton, 1993), all of which are either areas that are being actively collected and researched or not well explored or documented. The Dunvegan Formation is the furthest north of the known Cenomanian-aged vertebrate fossilbearing terrestrial units in North America and is therefore of particular interest for testing proposed latitudinal faunal provinciality in the early Late Cretaceous (e.g. Lehman, 2001; Sampson et al., 2010) and understanding its origin.

\section{Materials and methods}

CMN 59667 was loaned to the Royal Ontario Museum for preparation and study. Mechanical preparation using air scribes exposed the bones from the surrounding matrix. Parts of several bones were preserved as natural impressions of their external surface in the sandstone block, in which threedimensional fossil bone itself had been weathered away. The easy-to-interpret impressions of the rib shafts were left in place, but a portion of what turned out to be a neural arch was more complex and difficult to interpret as an impression. In order to recover this anatomical data, the impression was used as a natural mold and infilled with grey epoxy putty. Preparation then proceeded to the epoxy cast of the natural mold surface, providing a complete surface view of the right lateral side of the neural arch.

Several of us (Victoria M. Arbour, Derek Larson, and David Evans) undertook a brief visit in May 2019 to outcrops near the junction of the Murray and Pine rivers (the site of origin for the specimen) to attempt to relocate the original site where the fossil had been collected and collect geological and stratigraphic data at the locality (Fig. 1a). River levels were high, preventing extensive exploration of the steep cliff-forming outcrops.

\section{Institutional abbreviations}

AMNH - American Museum of Natural History, New York, New York, USA; CMN - Canadian Museum of Nature, Ottawa, Ontario, Canada; IVPP - Institute for Vertebrate Paleontology and Paleoanthropology, Beijing, China; MPC Mongolian Palaeontological Center (KID - Korea International Dinosaur Project field numbers), Ulaanbaatar, Mongolia; MU - University of Missouri, Columbia, Missouri, USA; NHMUK - Natural History Museum, London, UK; PIN - Paleontological Institute, Russian Academy of Sciences, Moscow, Russia; RBCM - Royal BC Museum, Victoria, British Columbia, Canada; ROM - Royal Ontario Museum, Toronto, Ontario, Canada; XHPM - Dalian Xinghai Palaeontological Museum, Liaoning, China; YPM - Yale Peabody Museum of Natural History, New Haven, Connecti- cut, USA; ZMNH - Zhejiang Museum of Natural History, Hangzhou, China.

\section{Geological setting}

CMN 59667 was collected by Merton Yarwood Williams in 1930; this was likely during a survey he headed, the NonMetallic Mineral Investigation on the Pacific Great Eastern Railway Survey of Resources of the Peace River, West Cariboo and West Lillooet Blocks, B.C., during the summers of 1929 and 1930 (Hives, 1988). Notes associated with CMN 59667 indicate it was collected " 1 mile below junction of Murray and Pine Rivers (Peace River district)". Charles M. Sternberg later that year identified the block as containing an anterior dorsal vertebra and rib fragment of an ornithischian resembling Camptosaurus, according to the label associated with the specimen.

The early to middle Cenomanian Dunvegan Formation crops out in this area. The Dunvegan Formation represents a major deltaic complex deposited over the span of about 2 million years (Plint, 2000). Characterized by a succession of alluvial and shallow marine sandstones, siltstones, and shales, it has an interfingering and diachronous relationship with the underlying marine Shaftesbury Formation and overlying marine Kaskapau Formation (Bhattacharya, 1994; Plint, 2000).

We undertook a reconnaissance field trip to the Pine RiverMurray River area in May 2019 to document the lithology and fossils of the original collection area. We were able to access the west bank of the Pine River on foot $1.3 \mathrm{~km}$ downstream from its junction with the Murray River, very close to the locality described in the original notes associated with the specimen. The east bank of the river exposes a large section of Dunvegan Formation approximately $22 \mathrm{~m}$ thick (Fig. 1e). At the base of the cliff we observed a distinctive orangestained palaeosol overlain by two thin dark-grey coal seams or palaeosols. Above these layers, there were seven packages of fine-grained sediments overlain by a more resistant layer of sandstone. The west side of the river lacks cliff-forming outcrop, but small outcrops are present as well as abundant loose pieces of sandstone.

Although we did not encounter any additional vertebrate bone, we observed current ripple marks, siderite nodules, and abundant ichnofossils, including vertically oriented burrows, shallow surface burrows or feeding traces, and the dinosaur ichnotaxon Tetrapodosaurus (RBCM P1473), made by a nodosaurid ankylosaur (Fig. 1b). Previously, Storer (1975) described a slab with tridactyl dinosaur footprints discovered on the north bank of the Pine River "at the site of the present bridge at East Pine", very close to the reported collection locality of CMN 59667. These were identified as Colombosauripus ungulatus and interpreted as belonging to a small coelurosaur similar to an ornithomimid. Terrestrial vertebrate footprints and trackways are widespread throughout the Dunvegan formation (both geographically and strati- 
graphically) and include tracks made by turtles, crocodilians, nodosaurs (Tetrapodosaurus), large ornithopods, small theropods (cf. Irenichnites; Columbosauripus), mediumsized theropods (cf. Magnoavipes), and birds; tracks attributed to large theropods have yet to be reported (McCrea et al., 2014). Plant remains in this area included leaf compressions (including the representative samples we collected, RBCM P1028-P1032), carbonized leaves and cones, and wood impressions (Fig. 1c, d, f). These sedimentological and palaeontological features are consistent with the upper twothirds of allomember E of the Dunvegan Formation, dominated by lakes, crevasse deltas, and poorly drained palaeosols (Lumsdon-West and Plint, 2005). This region would have been located at about $60^{\circ} \mathrm{N}$ during the Cenomanian (van Hinsbergen et al., 2015).

\section{Systematic palaeontology}

Dinosauria Owen, 1842

Ornithischia Seeley, 1887

Thyreophora Nopcsa, 1915

Ankylosauria Osborn, 1923

Ankylosauria indet.

\section{Material}

CMN 59667 consists of the posterior half of a dorsal vertebral centrum, an almost complete dorsal neural arch, and small sections of two dorsal ribs. All of these bones occur closely associated within a single small block of sandstone, and their size and morphology are consistent with being from a single individual, despite the lack of articulation.

\section{Locality and horizon}

CMN 59667 was collected from Dunvegan Formation exposures along the Pine River, $\sim 1.6 \mathrm{~km}$ north of the junction of the Murray and Pine rivers; precise coordinates are on file at the CMN. CMN 59667 is hosted in a dark-grey, mediumgrained litharenite.

\section{Description and comparisons}

Preserved in association in the block are a partial dorsal neural arch and a centrum in close proximity but disarticulated, so it is unclear whether these represent a single vertebra or are parts of two vertebrae (Fig. 2, Table 1). The centrum is taller than wide as preserved on the centrum face. It is constricted at the mid-length, giving it an hourglass-like appearance (Fig. 3b). Although one of the articular faces is damaged, the anterior and posterior ends of the centrum are dorsoventrally offset from each other.
Table 1. Vertebral measurements of CMN 59667 (in millimetres)

\begin{tabular}{lr}
\hline Centum, height of posterior face & 70.1 \\
Centrum, width of posterior face & 59.2 \\
Centrum, minimum width at constriction (as preserved) & 27.2 \\
Neural spine, height above postzygapophysis & 65.3 \\
Neural spine, anteroposterior length and mid-height & 73.7 \\
Transverse process, width at distal end & 44.2 \\
Diapophyseal groove, length (as preserved) & 30.3 \\
Diapophyseal groove, width at mid-length & 9.5 \\
\hline
\end{tabular}

The neural arch includes the right transverse process, neural spine, and right postzygapophysis. The neural spine is dorsoventrally low, mediolaterally narrow, and anteroposteriorly long, with an overall square outline (Fig. 2a-b). The dorsal edge of the neural spine is lightly rugose but not strongly mediolaterally expanded. The transverse process is broken and slightly offset from the neural arch but would have been slightly dorsally directed. The diapophysis is located ventrally on the transverse process towards its distal terminus and is an elongate, triangular groove (Fig. 3c).

Two partial dorsal rib shafts closely associated with the vertebral remains are preserved in the block (Fig. 2c-d). The largest section of rib is preserved in part as an impression in the sandstone block. The preserved portion of the fossil $(133.4 \mathrm{~mm})$ is $78 \%$ of the total length of the section, including the impression $(17.1 \mathrm{~mm})$. The shaft is anteroposteriorly broad and robust, with an oval cross section that measures $32.2 \mathrm{~mm}$ wide and $8.7 \mathrm{~mm}$ tall (measured at its distal-most end). The flat lateral and medial surfaces indicate that the preserved section originated from the mid to distal end of the rib. The second rib is represented by an $80.5 \mathrm{~mm}$ thin splint of preserved bone from its anterior or posterior margin. The long axis of the second rib measures $160.3 \mathrm{~mm}$ long (including its impression), is oriented parallel to the first rib, and is on the same plane, suggestive of articulation.

CMN 59667 is identified here as an ankylosaur based on several aspects of its vertebral morphology. In iguanodontians and ceratopsians, the neural spine of the dorsal vertebrae is relatively dorsoventrally tall and elongate and anteroposteriorly short. The preserved neural spine of CMN 59667, in contrast, is dorsoventrally short but anteroposteriorly long, with a square outline in lateral view (Fig. 3a). This morphology is typical of the dorsals of ankylosaurs (Fig. 4), such as Akainacephalus (Wiersma and Irmis, 2018), Ankylosaurus (AMNH 5895; Carpenter, 2004; Fig. 4c), Euoplocephalus (AMNH 5337; Arbour and Currie, 2013; Fig. 4b), Polacanthus (Blows, 1987), Sauropelta (Ostrom, 1970), and Europelta (Kirkland et al., 2013). Most importantly, the morphology of the transverse process in CMN 59667 is most similar to ankylosaurs compared with other ornithischians. In most ornithischians, the cross section of the distal transverse process is triangular or t-shaped and lacks a diapophyseal sulcus. The grooved morphology in CMN 59667 is consistent 

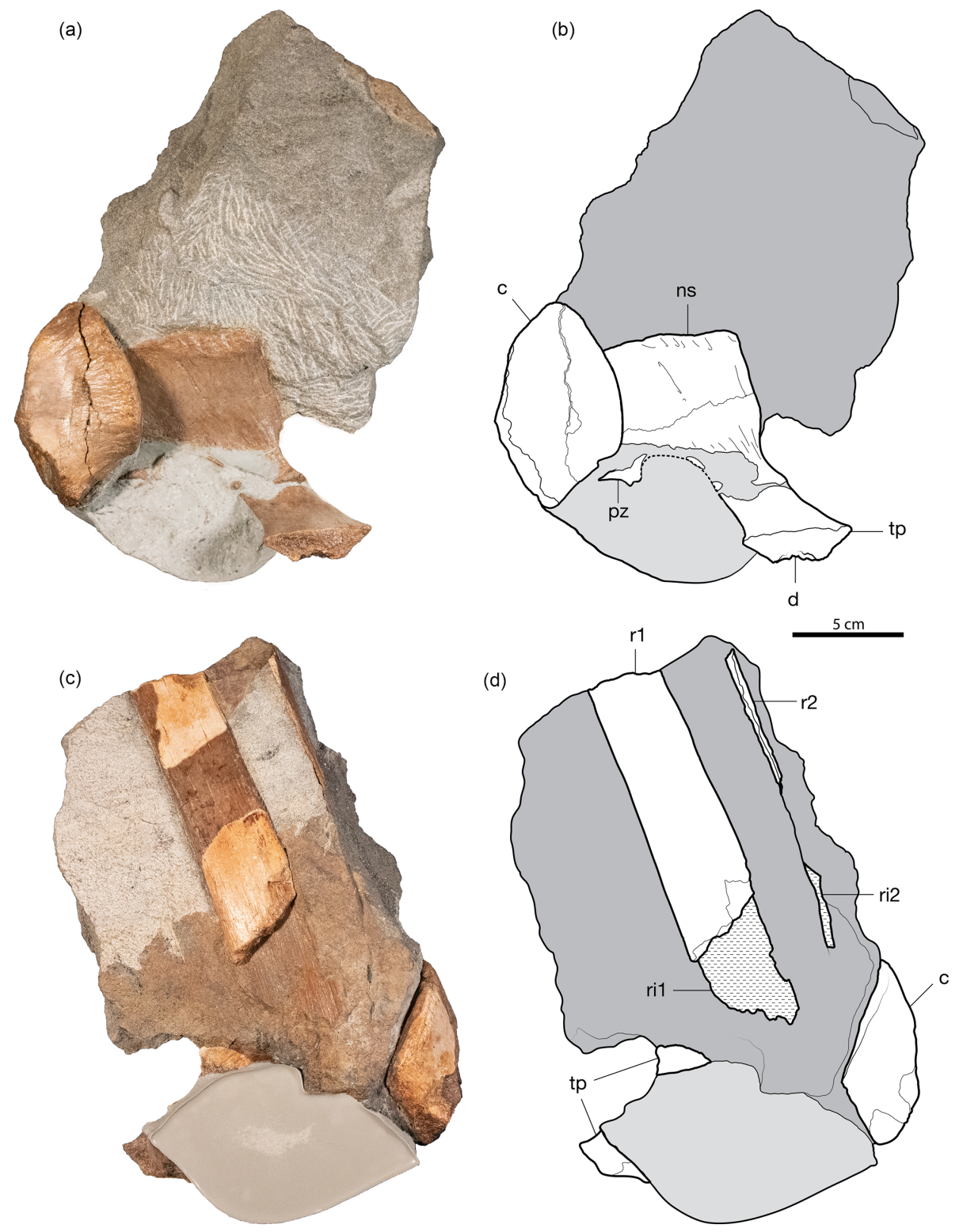

Figure 2. CMN 59667, block including portions of two ankylosaur dorsal vertebrae and two probable ankylosaur ribs. (a) Photograph and (b) interpretive illustration of isolated centrum (lateral view) and isolated neural arch (oblique dorsolateral view). (c) Reverse side of block, showing remains of two ribs and parts of the vertebrae, and (d) interpretive illustration of the same. Abbreviations are as follows: c centrum; $\mathrm{d}$ - diapophysis; $\mathrm{ns}$ - neural spine; pz - postzygapophysis; tp - transverse process; $\mathrm{r} 1$ - rib 1 ; r2 - rib 2; ri1 - impression of rib 1 .

with the typical morphology of the transverse process found in ankylosaurids (Fig. 4), such as Akainacephalus (Wiersma and Irmis, 2018), Ankylosaurus (AMNH 5895; Carpenter, 2004), Euoplocephalus (AMNH 5337; Arbour and Currie, 2013), and cf. Talarurus (MPC KID 155), which accepts the rib head; this groove seems to be absent in many nodosaurid ankylosaurs, such as Europelta (Kirkland et al., 2013), Hungarosaurus (Ősi, 2005), Peloroplites (Carpenter et al., 2008), Polacanthus (NHMUK R9293), and Silvisaurus (Carpenter and Kirkland, 1998). We are unaware of this morphology in any other group of ornithischian dinosaurs as well. The incomplete ribs of CMN 59667 are consistent with the morphology seen in other large-bodied ornithischian dinosaurs that are known from middle Cretaceous strata of North America, including ankylosaurs and iguanodontians, but cannot be identified more precisely.

\section{Discussion}

Although the Early to mid-Cretaceous dinosaur fossil record of western Canada is currently less well documented (Brown et al., 2015) in comparison to the southwestern United States, 


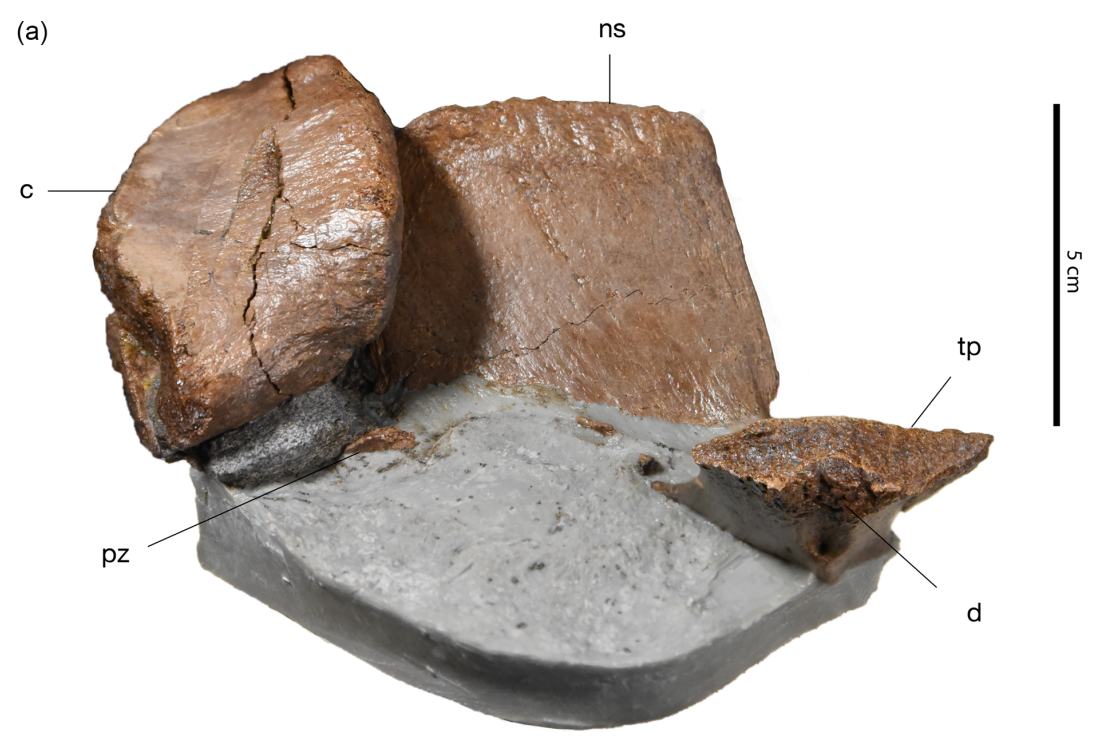

(b)

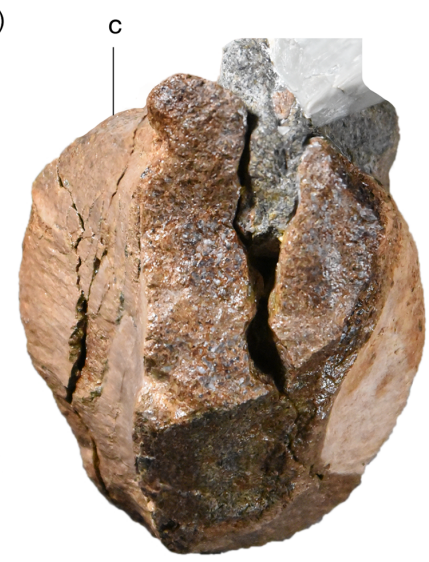

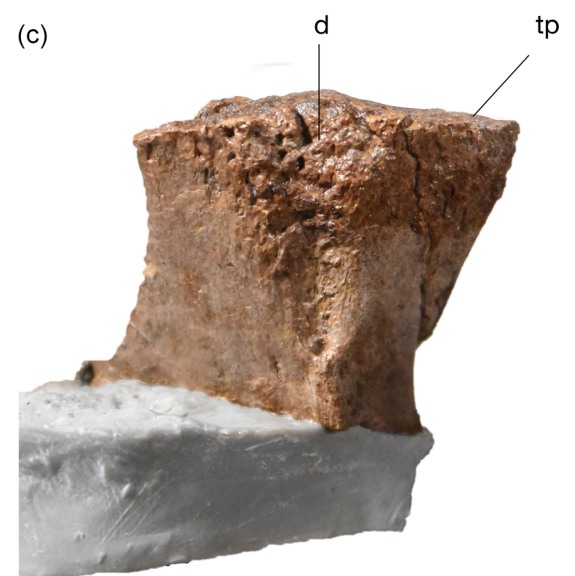

Figure 3. Details of vertebrae of CMN 59667. (a) Right lateral view of isolated neural arch (with oblique ventrolateral view of adhering isolated centrum), showing the diapophyseal sulcus on the transverse process. (b) Axial view of the isolated centrum, broken at its approximate mid-length, showing strong constriction of the centrum. (c) Ventral view of the transverse process of the isolated neural arch, showing the diapophyseal sulcus. Abbreviations are as follows: $\mathrm{c}$ - centrum; $\mathrm{d}$ - diapophysis; ns - neural spine; pz - postzygapophysis; tp - transverse process.

recent discoveries reveal the potential for much more information to be gleaned from this time period. Notably, the Early and mid-Cretaceous dinosaur skeletal record of western Canada is almost entirely represented by ankylosaurs, including osteoderms from the Berriasian-aged Pocaterra Creek Member of the Cadomin Formation in the Rocky Mountains of southwest Alberta (Nagesan et al., 2020), the exceptionally preserved Borealopelta from the Aptian Clearwater Formation (Brown et al., 2017), and isolated ossicles from the Dunvegan Formation of Alberta (Burns and Vavrek, 2014).
Ankylosaur skeletal fossils are widespread across North America during the Campanian-Maastrichtian, but they are never common components of the fossil record for a given formation. Even in the well-sampled Dinosaur Park Formation of southern Alberta, ankylosaurs make up less than $15 \%$ of the skeletal record (Brinkman et al., 1998, 2005). Although similar statistical analyses or censuses have yet to be undertaken for many Early and mid-Cretaceous formations in North America, ankylosaurs appear to make up a greater proportion of the ornithischian fauna compared to the Campanian-Maastrichtian in several localities (e.g. Britt et al., 2009). Most Early and mid-Cretaceous Laramidian ankylosaurs were nodosaurids (Carpenter and Kirkland, 1998; Arbour et al., 2016; Brown et al., 2017), with only a single ankylosaurid, Cedarpelta bilbeyhallorum, known from 
(a)

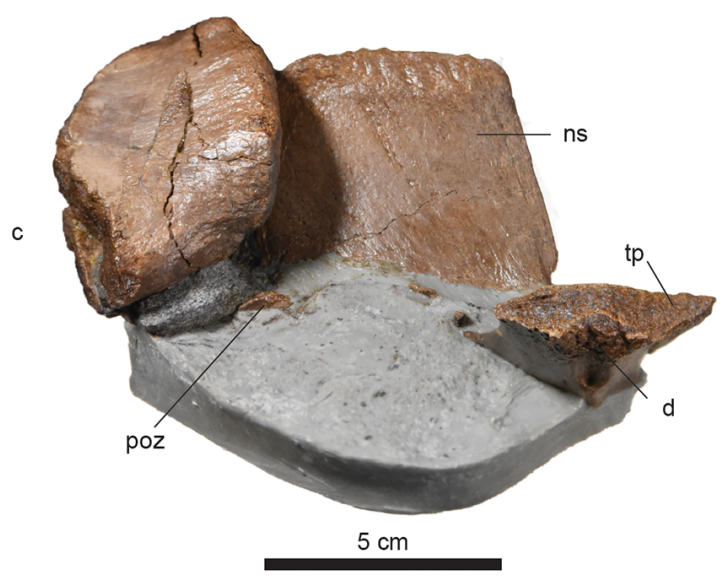

(b)

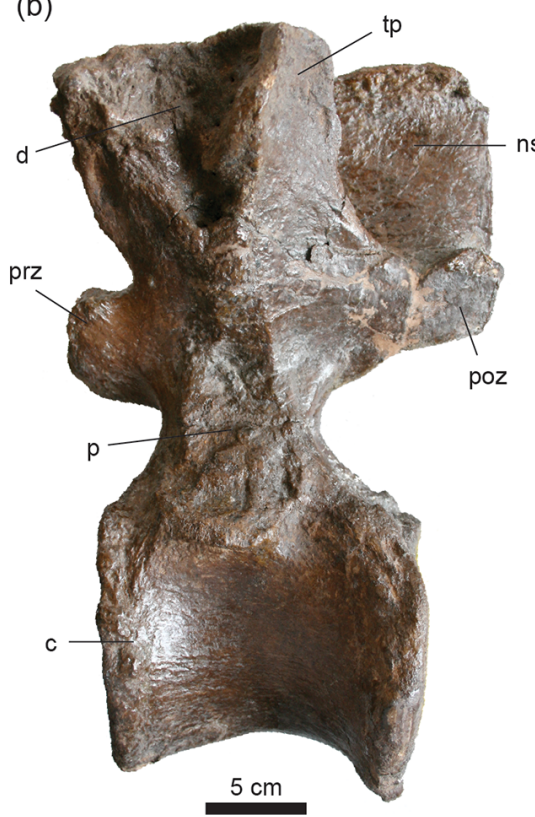

(c)

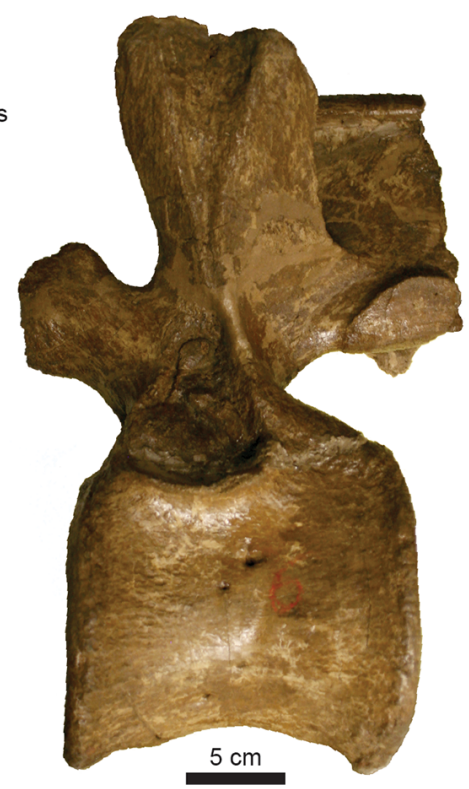

Figure 4. CMN 59667 compared to other ankylosaur dorsal vertebrae. (a) Right lateral view of isolated neural arch of CMN 59667, Ankylosauria indet. (b) Left lateral view of third dorsal vertebra from AMNH 5337, Euoplocephalus tutus. (c) Left lateral view of seventh dorsal vertebra of AMNH 5895, Ankylosaurus magniventris. Abbreviations are as follows: c - centrum; d - diapophysis; ns - neural spine; $\mathrm{p}$ parapophysis; poz - postzygapophysis; prz - prezygapophysis; tp - transverse process.

the Cenomanian-aged Mussentuchit Member of the Cedar Mountain Formation (Carpenter et al., 2001, 2008).

Ankylosaur footprints are also rare during the CampanianMaastrichtian of North America, with only a few potential records from the Blackhawk Formation of Utah (McCrea et al., 2001), the Wapiti Formation of northern Alberta (Fanti et al., 2013), and the Chignik Formation of Alaska (Fiorillo et al., 2019). In contrast, the ichnotaxon Tetrapodosaurus, generally considered to have been made by tetradactyl ankylosaurs (McCrea et al., 2001, 2014), is widespread in North America during the Early and mid-Cretaceous, with records from the Nanushuk and Chandler formations of Alaska (McCrea et al., 2001; May and Druckenmiller, 2009); the Gates and Dunvegan formations of Alberta (McCrea et al., 2001); the Gorman Creek, Gething, Dunvegan, Gates, and Kaskapau formations of British Columbia (McCrea et al., 2001, 2014); the Dakota Group of Colorado (Lockley and Gierlinski, 2014); the Naturita and Cedar Mountain formations of Utah (Lockley et al., 1999, 2018); and the Ross River Block in the Yukon (Gangloff et al., 2004). Given the rarity of ankylosaurian footprints in the Campanian-Maastrichtian of North America but their abundance in the Early and midCretaceous (including the Dunvegan Formation), it is notable that the only dinosaur skeletal material thus far described from the Dunvegan Formation, both recorded here and by Burns and Vavrek (2014), is ankylosaurian in nature.

The ichnofauna of the Dunvegan Formation is dominated by Tetrapodosaurus (McCrea et al., 2014), but lit- tle is known about its presumed trackmaker because skeletal material from this formation is extremely rare. Both nodosaurid and ankylosaurid ankylosaurs have five functional manual digits, but the number of pedal digits differs between these clades. Four pedal digits are present in the nodosaurids Niobrarasaurus (MU 650 VP; Carpenter et al., 1995), Nodosaurus (YPM 1815; Lull, 1921; Carpenter and Kirkland, 1998), and Sauropelta (AMNH 3032; Ostrom, 1970). In contrast, only three pedal digits are present in the ankylosaurids Anodontosaurus (AMNH 5266; Coombs, 1986), Dyoplosaurus (ROM 784; Arbour et al., 2009), Liaoningosaurus (IVPP V12560; Xu et al., 2001; XHPM1206; Ji et al., 2016), Pinacosaurus (multiple individuals from Alag Teeg, Currie et al., 2011), "Zhejiangosaurus" (ZMNH M8718; Lü et al., 2007), and the indeterminate articulated Mongolian ankylosaurids MPC 100/1305D (Carpenter et al., 2011) and PIN 614 (Maleev, 1954); Maleev (1956) reports Talarurus PIN 557-3 as having four digits in the pes, but this specimen is composed of multiple individuals, and it is unclear how the pedal elements were associated in situ. No tetradactyl ankylosaurids are known, and as such the tetradactyl prints represented by Tetrapodosaurus are unlikely to have been made by an ankylosaurid ankylosaur.

Based on the prevalence of Tetrapodosaurus in the Dunvegan Formation (McCrea et al., 2014), including at the CMN 59667 locality (e.g. RBCM P1473), and the fact that its trackmaker was probably not an ankylosaurid ankylosaur, we might expect ankylosaur skeletal material from the Dunvegan 
Formation to derive from a nodosaurid ankylosaur. However, the preserved transverse process of CMN 59667 has a diapophyseal sulcus on its ventral side, a feature that seems to be present in ankylosaurids but absent in nodosaurids. The distribution of the diapophyseal sulcus within ankylosaurs requires additional specimens and investigation, and CMN 59667 is too fragmentary to confidently assess its affinities within Ankylosauria. Nevertheless, the presence of both nodosaurids and ankylosaurids further south in North America during the Cenomanian means that an ankylosaurid identification for this specimen cannot be ruled out, despite the prevalence of nodosaurid footprints in the Dunvegan Formation. Burns and Vavrek (2014) were similarly cautious in their taxonomic appraisal of isolated ankylosaur ossicles from Dunvegan outcrops in Alberta, noting that the morphology and histology of such small elements cannot be as easily mapped to higher-level clades in comparison to larger ankylosaur osteoderms. We note, however, that the ossicles reported by Burns and Vavrek (2014) are extremely small ( $\sim 1 \mathrm{~mm}$ diameter), a size that is much more consistent with small interstitial osteoderms from ankylosaurid ankylosaurs such as Jinyunpelta (Zheng et al., 2018), Scolosaurus (NHMUK R5161; Nopcsa, 1928), and Zuul (ROM 75860; Arbour and Evans, 2017). Smaller interstitial osteoderms in nodosaurids are sometimes absent because of closer osteoderm packing (e.g. Borealopelta; Brown, 2017; Brown et al., 2017) or are $>8 \mathrm{~mm}$ in diameter, such as Sauropelta (AMNH 3032) and Panoplosaurus (CMN 2759).

The Cenomanian is a key stratigraphic interval for interpreting the palaeo-biogeographic and evolutionary history of ankylosaurid ankylosaurs. The earliest records of the characteristic tail club occur in Albian to Cenomanian-aged formations in Asia (Arbour and Currie, 2015; Zheng et al., 2018). Ankylosaurids are also first documented in North America during this time period in the Mussentuchit Member of the Cedar Mountain Formation but then disappear from the North American fossil record until the Santonian (Baszio, 1997; Eaton et al., 1999; Parrish, 1999), possibly indicating a response to high sea levels in Laramidia during the early Late Cretaceous (Arbour et al., 2016), although poor sampling in the Turonian-Santonian cannot be ruled out (e.g. Upchurch et al., 2011). In contrast, nodosaurids have a nearly continuous fossil record throughout the entire Cretaceous of North America (Arbour et al., 2016).

CMN 59667 represents the first associated skeletal material from a dinosaur recovered from the Dunvegan Formation. This new, well-preserved specimen therefore shows that this important taphonomic mode (articulated and associated skeletons, modes A1 and A2 of Eberth and Currie, 2005) can occur in the unit and raises the possibility that continued prospecting efforts could yield substantially more complete dinosaur material from this poorly known time interval in the Cretaceous fossil record of Canada. The presence or absence of ankylosaurids in the Dunvegan Formation can only be determined through the discovery of additional, more di- agnostic material, but the morphology of the currently known ankylosaur skeletal remains is tantalizing potential evidence for Cenomanian-aged ankylosaurids in Canada. Similarly, the discovery of unequivocal, diagnostic nodosaurid remains would provide the opportunity to link a trackmaker to the abundant Tetrapodosaurus trackways known from this formation.

Data availability. All specimens discussed within this paper are permanently reposited within museum collections. Precise locality data for CMN 59667 are on file at the Canadian Museum of Nature.

Author contributions. VMA, DL, and DE collected and analyzed the data. VMA wrote the manuscript, and all authors edited and revised the manuscript prior to submission.

Competing interests. The authors declare that they have no conflict of interest.

Acknowledgements. Many thanks to Peter May (Research Casting International) for alerting us to the existence of this specimen, to Jean Doherty and Michelle Coyne (GSC) for loan of the specimen to the ROM, and to Kieran Shepherd and Margaret Currie (CMN) for providing a catalogue number. Shino Sugimoto (ROM) expertly prepared CMN 59667, and Danielle Dufault (ROM) prepared the illustrations and figures. We are grateful to the landowner for permission to cross his private property to access the banks of the Pine River at the fossil locality.

Financial support. This research has been supported by the Natural Sciences and Engineering Research Council of Canada Discovery Grant to David Evans (RGPIN-2018-06788).

Review statement. This paper was edited by Torsten Scheyer and reviewed by Tom Raven and Attila Ôsi.

\section{References}

Arbour, V. M. and Currie, P. J.: Euoplocephalus tutus and the diversity of ankylosaurid dinosaurs in the Late Cretaceous of Alberta, Canada, and Montana, USA, PLoS ONE, 8, e62421, https://doi.org/10.1371/journal.pone.0062421, 2013.

Arbour, V. M. and Currie, P. J.: Ankylosaurid dinosaur tail clubs evolved through stepwise acquisition of key features, J. Anat., 227, 514-523, 2015.

Arbour, V. M. and Evans, D. C.: A new ankylosaurine dinosaur from the Judith River Formation of Montana, USA, based on an exceptional skeleton with soft tissue preservation, Roy. Soc. Open Sci., 4, 161086, https://doi.org/10.1098/rsos.161086, 2017.

Arbour, V. M. and Evans, D. C.: A new leptoceratopsid dinosaur from Maastrichtian-aged deposits of the Sustut 
Basin, northern British Columbia, Canada, Peer J., 7, e7926, https://doi.org/10.7717/peerj.7926, 2019.

Arbour, V. M. and Graves, M. C.: An ornithischian dinosaur from the Sustut Basin, north-central British Columbia, Canada, Can. J. Earth Sci., 45, 457-463, 2008.

Arbour, V. M., Burns, M. E., and Sissons, R. L.: A redescription of the ankylosaurid dinosaur Dyoplosaurus acutosquameus Parks, 1924 (Ornithischia: Ankylosauria) and a revision of the genus, J. Vertebr. Paleontol., 29, 1117-1135, 2009.

Arbour, V. M., Zanno, L. E., and Gates, T.: Ankylosaurian dinosaur palaeoenvironmental associations were influenced by extirpation, sea-level fluctuation, and geodispersal, Palaeogeogr. Palaeocl., 449, 289-299, 2016.

Ash, A., Ellis, B., Hickey, L. J., Johnson, K., Wilf, P., and Wing, S.: Manual of leaf architecture, Smithsonian Institution, Washington, D.C., Smithsonian Institution, 65 pp., 1999.

Avrahami, H. M., Gates, T. A., Heckert, A. B., Makovicky, P. J., and Zanno, L. E.: A new microvertebrate assemblage from the Mussentuchit Member, Cedar Mountain Formation: insights into the paleobiodiversity and paleobiogeography of early Late Cretaceous ecosystems in western North America, Peer J., 6, e5883, https://doi.org/10.7717/peerj.5883, 2018.

Baszio, S.: Systematic palaeontology of isolated dinosaur teeth from the latest Cretaceous of South Alberta, Canada, Cour. Forsch. Senck., 196, 33-77, 1997.

Bhattacharya, J. P.: Cretaceous Dunvegan Formation of the Western Canada Sedimentary Basin, in: Geological Atlas of the Western Canada Sedimentary Basin, edited by: Mossop, G. D. and Shetsen, I., Canadian Society of Petroleum Geologists and Alberta Research Council, 364-373, 1994.

Blows, W. T.: The armoured dinosaur Polacanthus foxi from the Lower Cretaceous of the Isle of Wight, Palaeontology 30, 557580, 1987.

Brinkman, D. B., Ryan, M. J., and Eberth, D. A.: The paleogeographic and stratigraphic distribution of ceratopsids (Ornithischia) in the Upper Judith River Group of western Canada, Palaios, 13, 160-169, 1998.

Brinkman, D. B., Russell, A. P., and Peng, J.-H.: Vertebrate microfossil sites and their contribution to studies of paleoecology, in: Dinosaur Provincial Park: a spectacular ancient ecosystem revealed, edited by: Currie, P. J. and Koppelhus, E. B., Indiana University Press, 88-98, 2005.

Britt, B. B., Eberth, D. A., Scheetz, R. D., Greenhalgh, B. W., and Stadtman, K. L.: Taphonomy of debris-flow hosted dinosaur bonebeds at Dalton Wells, Utah (Lower Cretaceous, Cedar Mountain Formation, USA), Palaeogeogr. Palaeocl., 280, 1-22, 2009.

Brown, C. M.: An exceptionally preserved armored dinosaur reveals the morphology and allometry of osteoderms and their horny epidermal coverings, Peer J., 5, e4066, https://doi.org/10.7717/peerj.4066, 2017.

Brown, C. M., Ryan, M. J., and Evans, D. C.: A census of Canadian dinosaurs: more than a century of discovery, in: All animals are interesting: a festschrift celebrating the career of Anthony P. Russell, edited by: Bininda-Emonds, O. R. P., Powell, G. L., Jamniczky Bauer, A. M., and Theodor, J. M., BIS-Verlag der Carl von Ossietzky Universität, Oldenburg, Germany, 151-209, 2015.

Brown, C. M., Henderson, D. M., Vinther, J., Fletcher, I., Sistiaga, A., Herrera, J., and Summons, R. E.: An exceptionally pre- served three-dimensional armored dinosaur reveals insights into coloration and Cretaceous predator-prey dynamics, Curr. Biol., 27, 2514-2521, 2017.

Burns, M. E. and Vavrek, M. J.: Probable ankylosaur ossicles from the middle Cenomanian Dunvegan Formation of northwestern Alberta, Canada, PLOS ONE, 9, e96075, https://doi.org/10.1371/journal.pone.0096075, 2014.

Carpenter, K.: Redescription of Ankylosaurus magniventris Brown 1908 (Ankylosauridae) from the Upper Cretaceous of the Western Interior of North America, Can. J. Earth Sci., 41, 961-986, 2004.

Carpenter, K. and Kirkland, J. I.: Review of Lower and middle Cretaceous ankylosaurs from North America, N. M. Mus. Nat. Hist. Sci. Bull., 14, 249-270, 1998.

Carpenter, K., Dilkes, D., and Weishampel, D. B.: The dinosaurs of the Niobrara Chalk Formation (Upper Cretaceous, Kansas), J. Vertebr. Paleontol., 15, 275-297, 1995.

Carpenter, K., Kirkland, J. I., Burge, D., and Bird, J.: Disarticulated skull of a new primitive ankylosaurid from the Lower Cretaceous of eastern Utah, in: The Armored Dinosaurs, edited by: Carpenter, K., Indiana University Press, 211-238, 2001.

Carpenter, K., Bartlett, J., Bird, J., and Barrick, R.: Ankylosaurs from the Price River Quarries, Cedar Mountain Formation (Lower Cretaceous), east-central Utah, J. Vertebr. Paleontol., 28, 1089-1101, 2008

Carpenter, K., Hayashi, S., Kobayashi, Y., Maryańska, T., Barsbold, R., Sato, K., and Obata, I.: Saichania chulsanensis (Ornithischia, Ankylosauridae) from the Upper Cretaceous of Mongolia, Palaeontogr. Abt. A, 293, 1-161, 2011.

Cook, T. D., Wilson, M. V. H., and Murray, A. M.: A middle Cenomanian euselachian assemblage from the Dunvegan Formation of northwestern Alberta, Can. J. Earth Sci., 45, 1185-1197, 2008.

Coombs, W. P.: A juvenile ankylosaur referable to the genus $\mathbf{E u}$ oplocephalus (Reptilia, Ornithischia), J. Vertebr. Paleontol., 6, 162-173, 1986.

Currie, P. J., Badamgarav, D., Koppelhus, E. B., Sissons, R., and Vickaryous, M. K.: Hands, feet, and behaviour in Pinacosaurus (Dinosauria: Ankylosauridae), Acta Palaeontol. Pol., 56, 489504, 2011.

Eaton, J. G.: Therian mammals from the Cenomanian (Upper Cretaceous) Dakota Formation, southwestern Utah, J. Vertebr. Paleontol., 13, 105-124, 1993.

Eaton, J. G., Diem, S., Archibald, J. D., Schierup, C., and Munk, H.: Vertebrate paleontology of the Upper Cretaceous rocks of the Markagunt Plateau, southwestern Utah, Miscellaneous Publication 99-1, Utah Geological Survey, 323-333, 1999.

Eaton, T. H.: A new armored dinosaur from the Cretaceous of Kansas, Univ. Kansas Paleontol. Contrib., 8, 1-24, 1960.

Eberth, D. A. and Currie, P. J.: Vertebrate taphonomy and taphonomic modes, in: Dinosaur Provincial Park: a spectacular ancient ecosystem revealed, edited by: Currie, P. J. and Koppelhus, E. B., Indiana University Press, 453-477, 2005.

Fanti, F., Bell, P. R., and Sissons, R. L.: A diverse, high-latitude ichnofauna from the Late Cretaceous Wapiti Formation, Alberta Canada, Cret. Res., 41, 256-269, 2013.

Fiorillo, A. R., Kobayashi, Y., McCarthy, P. J., Tanaka, T., Tykoski, R. S., Lee, Y.-N., Takasaki, R., and Yoshida, J.: Dinosaur ichnology and sedimentology of the Chignik Formation (Upper Cretaceous), Aniakchak National Monu- 
ment, southwestern Alaska; further insights on habitat preferences of high-latitude hadrosaurs, PLOS ONE, 14, e0223471, https://doi.org/10.1371/journal.pone.0223471, 2019.

Gangloff, R. A., May, K. C., and Storer, J. E.: An early Late Cretaceous dinosaur tracksite in central Yukon Territory, Canada, Ichnos, 11, 299-309, 2004.

Hay, M. J., Cumbaa, S. L., Murray, A. M., and Plint, A. G.: A new paraclupeid fish (Clupeomorpha, Ellimmichthyiformes) from a muddy marine pro-delta environment: middle Cenomanian Dunvegan Formation, Alberta, Canada, Can. J. Earth Sci., 44, 775$790,2007$.

Hives, C.: M. Y. Williams fonds, University of British Columbia Archives, 50 pp., 1988.

Ji, Q., Wu, X., Cheng, Y., Ten, F., Wang, X., and Ji, Y.: Fish hunting ankylosaurs (Dinosauria, Ornithischia) from the Cretaceous of China, J. Geol., 40, 183-190, 2016.

Kirkland, J. I., Alcalá, L., Loewen, M. A., Espílez, E., Mampel, L., and Wiersma, J. P.: The basal nodosaurid ankylosaur Europelta carbonensis n. gen., n. sp. from the Lower Cretaceous (Lower Albian) Escucha Formation of northeastern Spain, PLOS ONE, 8, e80405, https://doi.org/10.1371/journal.pone.0080405, 2013.

Krumenacker, L. J., Varricchio, D. J., Wilson, J. P., Martin, A., and Ferguson, A.: Taphonomy of and new burrows from Oryctodromeus cubicularis, a burrowing neornithischian dinosaur, from the mid-Cretaceous (Albian-Cenomanian) of Idaho and Montana, USA, Palaeogeogr. Palaeocl., 530, 300-311, 2019.

Lehman, T. M.: Late Cretaceous dinosaur provinciality, in: Mesozoic Vertebrate Life, edited by: Tanke, D. H. and Carpenter, L., Indiana University Press, 310-328, 2001.

Lockley, M. G. and Gierlinski, G. D.: Notes on a new ankylosaur track from the Dakota Group (Cretaceous) of northern Colorado, New Mexico Mus. Nat. Hist. Sci. Bull., 62, 301-306, 2014.

Lockley, M., Burton, R., and Grondel, L.: A large assemblage of tetrapod tracks from the Cretaceous Naturita Formation, Cedar Canyon region, southwestern Utah, Cret. Res., 92, 108-121, 2018.

Lockley, M. G., Kirkland, J. I., DeCourten, F. L., Britt, B. B., and Hasiotis, S. T.: Dinosaur tracks from the Cedar Mountain Formation of eastern Utah: a preliminary report, in: Vertebrate Paleontology in Utah, edited by: Gilette, D. D., Geol. Soc. Am., Miscellaneous Publication 99-1, 253-258, 1999.

Lü, J., Jin, X., Sheng, Y., Li, Y., Wang, G., and Azuma, Y.: New nodosaurid dinosaur from the Late Cretaceous of Lishui, Zhejiang Province, China, Acta Geol. Sin., 81, 344-350, 2007.

Lull, R.: The Cretaceous armored dinosaur, Nodosaurus textilis Marsh, Am. J. Sci. Ser., 5, 97-126, 1921.

Lumsdon-West, M. P. and Plint, A. G.: Changing alluvial style in response to changing accommodation rate in a proximal foreland basin setting: Upper Cretaceous Dunvegan Formation, north-east British Columbia, Canada, in: Fluvial Sedimentology VII, edited by: Blum, M. D., Marriott, S. B., and Leclair, S. F., Int. As. Sed., IAS Special Publication 35, 493-515, 2005.

Maleev, E. A.: The armored dinosaurs of the Cretaceous period in Mongolia (Family Syrmosauridae), Dokl. Akad. Nauk SSSR, 48, 142-170, 1954 (in Russian; translation by Robert Welch).

Maleev, E. A.: Armored dinosaurs of the Upper Cretaceous of Mongolia, Family Ankylosauridae, Trudy Paleontol. Inst. Akad. Nauk SSSR, 62, 51-91, 1956 (in Russian; translation by R. Welch).
May, K. C. and Druckenmiller, P. S.: A dinosaurian ichnofossil assemblage from the Nanushuk Formation, National Petroleum Reserve - Alaska, The Alaska Geological Society 2009 Technical Conference Abstracts Volume, 32 pp., 2009.

McCrea, R. T. and Buckley, L. G.: Excavating British Columbia's first dinosaurs and other palaeontological projects in the Tumbler Ridge area, Alberta Palaeontological Society Eighth Annual Symposium, Calgary, Alberta, Canada, March 2004, 24-33, 2004.

McCrea R. T., Lockley, M. G., and Meyer, C. A.: Global distribution of purported ankylosaur track occurrences, in: The Armored Dinosaurs, edited by: Carpenter, K., Indiana University Press, 413454, 2001.

McCrea, R. T., Buckley, L. G., Plint, A. G., Currie, P. J., Haggart, J. W., Helm, C. W., and Pemberton, S. G.: A review of vertebrate track-bearing formations from the Mesozoic and earliest Cenozoic of western Canada with a description of a new theropod ichnospecies and reassignment of an avian ichnogenus, New Mexico Mus., Nat. Hist. Sci. Bull., 62, 5-93, 2014.

Nagesan, R. S., Campbell, J. A., Pardo, J. D., Lennie, K. I., Vavrek, M. J., and Anderson, J. S.: An Early Cretaceous (Berriasian) fossil-bearing locality from the Rocky Mountains of Alberta, yielding the oldest dinosaur skeletal remains from western Canada, Can. J. Earth Sci., 57, 542-552, 2020.

Nopcsa, F.: Die dinosaurier der Siebenbürgischen Landesteile Ungarns, Mit. A. d. Jahrb. D. kgl. Ungar. Geolog. Reichsanst., 23, 1-26, 1915.

Nopcsa, B. F.: Palaeontological notes on reptiles, V. On the skull of the Upper Cretaceous dinosaur Euoplocephalus, Geol. Hungarica, Ser. Palaeontol., 1, 1-84, 1928.

Noto, C. R., Main, D. J., and Drumheller, S. K.: Feeding traces and paleobiology of a Cretaceous (Cenomanian) crocodyliform: example from the Woodbine Formation of Texas, Palaios, 27, 105115, 2012.

Osborn, H. F.: Two Lower Cretaceous dinosaurs from Mongolia, Am. Mus. Novit., 95, 1-10, 1923.

Ősi, A.: Hungarosaurus tormai, a new ankylosaur (Dinosauria) from the Upper Cretaceous of Hungary, J. Vertebr. Paleontol., 25, 370-383, 2005.

Ostrom, J. H.: Stratigraphy and paleontology of the Cloverly Formation (Lower Cretaceous) of the Bighorn Basin Area, Wyoming and Montana, B. Peabody Mus. Nat. Hist., 35, 12-34, 1970.

Owen, R.: Report on British fossil reptiles, Reports of the British Association for the Advancement of Science, 11, 60-204, 1842.

Parrish, J. M.: Dinosaur teeth from the Upper Cretaceous (Turonian-Judithian) of southern Utah, in: Gillette DD (ed) Vertebrate paleontology in Utah, Geol. Soc. Am., 319-321, https://doi.org/10.1371/journal.pone.0012292, 1999.

Plint, A. G.: Sequence stratigraphy and paleogeography of a Cenomanian deltaic complex: the Dunvegan and lower Kaskapau formations in subsurface and outcrop, Alberta and British Columbia, Canada, B. Can. Petrol. Geol., 48, 43-79, 2000.

Rylaarsdam, J. R., Varban, B. L., Plint, A. G., Buckley, L. G., and McCrea, R. T.: Middle Turonian dinosaur paleoenvironments in the Upper Cretaceous Kaskapau Formation, northeast British Columbia, Can. J. Earth Sci., 43, 631-652, 2006.

Sampson, S. D., Loewen, M. A., Farke, A. A., Roberts, E. M., Forster, C. A., Smith, J. A., and Titus, A. L.: New horned dinosaurs from Utah provide evidence for in- 
tracontinental dinosaur endemism, PLOS ONE, 5, e12292, https://doi.org/10.1016/j.cretres.2020.104384, 2010.

Seeley, H. G.: On the classification of the fossil animals commonly named Dinosauria, Proc. R. Soc. Lond., 43, 165-171, 1887.

Storer, J.: Dinosaur tracks, Columbosauripus ungulatus (Saurischia: Coelurosauria), from the Dunvegan Formation (Cenomanian) of northeastern British Columbia, Can. J. Earth Sci., 12, 1805$1807,1975$.

Tucker, R. T., Zanno, L. E., Huang, H.-Q., and Makovicky, P. J.: A refined temporal framework for newly discovered fossil assemblages of the upper Cedar Mountain Formation (Mussentuchit Member), Mussentuchit Wash, Central Utah. Cret. Res., 110, 104384, https://doi.org/10.1371/journal.pone.012694, 2020.

Upchurch, P., Mannion, P. D., Benson, R. B., Butler, R. J., and Carrano, M. T.: Geological and anthropogenic controls on the sampling of the terrestrial fossil record: a case study from the Dinosauria, Geol. Soc. SP., 358, 209-240, 2011. van Hinsbergen, D. J. J., de Groot, L. V., van Schaik, S J., Spakman, W., Bijl, P. K., Sluijis, A., Langereis, C. G., and Brinkhuis, H.: A paleolatitude calculator for paleoclimate studies (model version 2.1), PLOS ONE, 10, e0126946, https://doi.org/10.1371/journal.pone.0126946, 2015.

Vavrek, M. J., Murray, A. M., and Bell, P. R.: An early Late Cretaceous (Cenomanian) sturgeon (Acipenseriformes) from the Dunvegan Formation, northwestern Alberta, Canada, Can. J. Earth Sci., 51, 677-681, 2014.

Wiersma, J. P. and Irmis, R. B.: A new southern Laramidian ankylosaurid, Akainacephalus johnsoni gen. et sp. nov., from the upper Campanian Kaiparowits Formation of southern Utah, USA Peer J., 6, e5016, https://doi.org/10.7717/peerj.5016, 2018.

Xu, X., Wang, X.-L., and You, H.-L.: A juvenile ankylosaur from China, Naturwissenschaften, 88, 297-300, 2001.

Zheng, W., Jin, X., Azuma, Y., Wang, Q., Miyata, K., and $\mathrm{Xu}, \mathrm{X}$.: The most basal ankylosaurine dinosaur from the Albian-Cenomanian of China, with implications for the evolution of the tail club, Sci. Rep. UK., 8, 3711, https://doi.org/10.1016/j.cretres.2020.104384, 2018. 